\title{
Marketing Predictions and Trends for Future
}

\author{
Prof. Dr. Erdoğan Taşkın (Beykent University, Turkey)
}

\begin{abstract}
Global competition gradually accelerates and particularly affects businesses' marketing activities. It is very important for businesses to capitalize on this fact by creating value in this ripe environment. While the world rapidly changes, business directors and especially marketing managers will focus more on future predictions and trends as the primary subjects of research. Businesses are reaching a crossroads of boom or bust for various reasons: important technological changes, a revolution in creative innovation, fierce global competition and continuously struggling marketing environment. First, the determination of the predictions affecting the business and the analysis of the trends begin with the collection of data in order to reach the marketing objectives. The analysis made afterwards attempts to determine the pattern of the trends or to examine the predictions within the information flow. In this study, initially thirty source publications have been used to determine the effective thoughts and original views which concern the future of the businesses. Then, research has been made on the predictions related to the future of marketing with four hundred persons working in the businesses. The rates of the most important thirteen variables which are thought to affect the future marketing activities have been statistically measured, summarized, and interpreted with six tables.
\end{abstract}

\section{Introduction}

Marketing, which creates customer value, should create correct relations with corresponding customers in the future as it does today. In the future, customer expenditures at the points of sale will differ, and the products they buy will change. Then, innovative products and creative services will be sold at high prices. The managers who create customer value and want to reach the pricing target need an up-to-date point of view for important reasons: in order to forecast the future, predict the events, estimate the market, allowing planning and direct activities with a new insight (Roubini, 2017).

First, and most important, of the management functions will be planning. These managers will examine, find, and plan the actions to be taken, followed by immediate action. Applications will be controlled instantly; the results will be analyzed, and the necessary arrangements will be made faster. Managers will diagnose current problems, find solutions, and remedy them. It will reduce the uncertainty and increase the flexibility. Firms will reduce costs and increase customer value, creating performance gains and achieving their objectives (Paul and Cox, 2003).

Marketing departments will continuously deal with planning, application, analysis and control functions. In particular, every manager who does planning will focus on future predictions and trends varying by the place, time and customers. The predictions stated here will vary much by the macro external environment of the firms and the micro environment of the marketing department. Firms will be affected by the environment much more.

\section{Firm Macro External Environment Factors Predictions}

To better understand, it is required to analyze the demographical, natural, economic, cultural, political and technological aspects of the overall business environment. Macro factors which should be examined are the powers which continuously affect the firm, causing change. Demographically, the structure, condition and dynamic features of the population (in a target country) to which they will do marketing are important for the firms. There are many variables of the population in that country, such as: man-woman, rural-urban, young-old, employedunemployed, region density, growth rate, age distribution pyramid, birth-marriage rates, internal and external migration, etc. The natural environment also plays a role. Soil, air, climate, forest, water, sea, raw material sources are among the macro environmental factors affecting marketing in the firms. Economic environment in the firms involves the general evaluation of: the country's economy, research of gross national product, per capita income, balance of payments, foreign exchange reserves, share of import and export in total economy, education and employment level, inflation rate, general demand level and the conditions of competition. Another environmental factor in the firms is the social and cultural environment. Low rate of sales in the firms may be caused by the political and legal environment, and the applications of state and political power which directly affect the marketing activities (Kotler and Armstrong, 2018).

Firms are formed by technology, market (globalization) and mother nature (climate change and decrease in biodiversity) which are three important factors today. At the same time, we are going through accelerating changes in business life, politics, geopolitics, ethnic changes, and society. Our world dramatically reshapes and reacts to these stimuli. Global events, international relations, regional, and local social movements in the external environment largely affect the firms. Fertility rates are dropping, and the population is getting older around the world. Current and probable customers of the firms are getting older. On the other hand, the market targeting older persons is better, as they spend more for the different products and innovative services offered by the firms in order to live more healthily (Friedman, 2012; Friedman, 2016). 
In a Board Directors study, customer-focused predictions have become prominent. Firms will communicate more effectively with their customers with the help of technology. Customers will almost instantly access the information they look for at the expert-level. Sales will be directed with smart connection points. They will determine the points at which the customer comes across the products and services. In the future, firms will supply more smart solutions and simple services according to the needs of the customers targeted by market planning.

For marketing activities, it will gain importance to make the customer appreciate the product and services offered rather than first attracting his/her attention. Products will be more adaptable according to the individual customer demands. Future products will be arranged according to the fluctuations in the needs of the customers and the change in the living status of the customers. It will be highly important to offer creative products according to the customers, to make service innovations regularly and to consider the sustainability in the other applications of the marketing mix (Diane and Schouten, 2014; Jánszky, 2017).

The newest trends will be globalization, strengthening of communication technology, sustainability, increases in the social responsibility of the firms, analyzing the psychology of the customers, cooperation of firms to produce value creating complex products and services within the economic systems. (The 5 Most Prominent Management Trends of the 21st Century, 2017).

In order to create customer value, it will be necessary to shape information and to connect the information to each other through the network. Information will increase the value of the customer. Firms will increase their income with their power to evaluate this data. Firms will make use of the available information while making marketing decisions. Firm management will need a new point of view. The skill to distinguish between the important and unimportant will become prominent in this point of view. It will be a problem which information is important, and how, where, when, by whom and by which method this information will be used to solve the problems of the firm (Peters, 2017; Leonhard, 2017).

Customer's use of the products or services, catching the big data flow from his/her needs, requests, desires, behaviors, wishes and demands and analyzing the patterns will be of vital importance for the purpose of creating customer value in the firms. It will be important to integrate the customer contact points throughout all distribution channels and to achieve marketing targets (Kotler, Kartajaya, Setiawan, 2017).

Firms will receive more intervention from the developing markets, changes in electronics, security problems and the changes in the customer demographics in different ways. After bringing together the correct technology and software in the corresponding area, the firms will use them to strengthen a second field. The best firms will be the ones that apply the technology correctly. The digital marketing field will completely change depending on the increase in the number of users of mobile communication devices. First, the sales representative in the field will immediately update the necessary changes to the customers' demand. Production, supply, shipment, customer, end consumer, end user will connect to each other instantly with lower cost through the applications such as cloud and cooperate. Second, mobile devices will be gradually developed more. Sales representative will be able to see the inventory of the firm buying their products. Thus, the orders will be immediately followed, and the missing products will be completed. The customers will not only talk to other customers, they will communicate with the other machines. Finally, the use of mobile devices by the customers to place orders or make payments will expand. Firms will reach from the minimum number of current customers to the maximum number of prospective customers using marketing tools on numerous social media sites, such as: AirBnB, Bootmakers, Cunsumerist, Dropbox, Facebook, Foursquare, Google+, Gizmodo, Hotmail, Instagram, LinkedIn, MySpace, Pinterest, Snapchat, Twitter, Vine, WeChat, Youtube, and Zenhabits. This method will be an essential marketing tool. In this way, target audience is reached with almost zero budget compared to traditional marketing (Friedman, 2012; Ranchhod, 2017).

When more discoveries are made through scientific research, more intelligent methods and new technologies will arise. Ways of cooperation, putting the skills gained in the firm into practice more, working with global firms, matrix organization structure, information collection and interpreting will become more prominent. In the future, analysis and interpretation of social media, problem solving, and innovation through creativity will gain importance. Protection of justice, honesty, transparency, reputation management, continuous loyalty, and firm ethical values in society, gaining spirituality and trust will become important cultural factors both for firms and all employees (Watson, 2012; Gunn, 2013).

In this new cultural environment, smart phones, laptop computers, developed tablets, innovative cars, ecological houses and all our items will inherently connect to each other with their interfaces thanks to the internet of the objects. Besides augmented reality applications, artificial intelligence, use of innovative robots, and virtual marketing from big data warehouses will connect the planet through the virtual network. Thus, marketing, which completely concentrates on value creating, will be unrecognizable. Not as it seems nor as experienced, and not as we read or suppose it to be. Regardless of the demographic, we will see more conscious efforts to learn the cooperation between the smart screens, suppliers, distribution channels and the time realization of the service in the firms working to offer experience to their customers. Suppliers of the firms will increase. Marketing will consider the technological trends in order to evaluate customer behaviors. Customers will want to connect and use 
the platforms, applications and devices providing the best answer to buy from the firms (Kurzweil, 2001; Friedman, 2016).

Firms will wait in hope for the services they offer to reach the customers from different customer connection points. Marketing activities will go beyond preaching and will be fun at the same time. All marketing activities from the content made available to the customers to the advertisements on the mobile devices will be more fun and humane. Firms will make their marketing experience humane. Budgets will be allocated for this. There will be changes in marketing decisions. Firms will need virtual marketers. Speaking, messaging with corporate discourse and boring, dull campaigns will be left in the past. Instead, we will start to see more people in all marketing activities. We will see videos, pictures with people and humor. The most valuable assets of the firms will be human capital and the most valuable treasure will be their employees. Competitor firms and the quality will increase. It will be more important for the firms to understand the employees, customers, society and people under these competition conditions (Wheelwright, 2011; Friedman, 2016; Jánszky, 2017).

Marketing will especially work to create connection network interactive with social media. Firms will understand that the most effective way to create customer value is to make the customers smile more, give confidence, and ensure loyalty in all media. An amazing communion and interaction will arise between some firms and their customers. However, this will realize only between the intelligent firms and the real target audience in the marketing applications. Firms will give more valid and more accurate information to their customers through social media, such as marketing blogs. Exciting, incredible changes will occur in virtual reality and integrated technologies in the firms. The capacity to understand the key trends in the future-shaping technology, customers, society and market will help the firm to survive. Intelligent firms will focus on single system, single communication and single world with the help of technology. This unity will be in the center of the understanding the new future. It will be understood better that the effect of interactive changes in the virtual environment to create value in marketing is very important (Stone, Woodcock 2014; Kotler, Kartajaya, Setiawan, 2017).

\section{Marketing Micro External Environment Factors Predictions}

Marketing management evaluates the predictions regarding the micro external environment factors. Strong factors affecting the micro environment are public opinion, suppliers, competitors, distributors and customers (Kotler and Armstrong, 2018).

While marketing management reaches all customers in a different way and with different content, it will pay attention not to break the marketing channels. Attention will be paid to do the correct things while using different social media channels. Target markets will be fundamental again. Targeting customers will be revaluated whether they are right for the position. The target market will be revaluated and the order of priority of sources will be sorted again rationally. Virtual marketing will continue conversion and promotional activities and the marketing communication will continue breakage. There will be bigger changes in virtual marketing. Marketing will consider making more sales. Firm managers will need to create extensive business experiences both depending on the virtual environment and outside the virtual environment. Marketing management will strive to answer the questions of the current or prospective customers and to create more online value. Virtual integrated marketing applications will be available in the fields such as social, mobile, advertising and marketing communication (Walsh, 2017; Dixon, 2017).

Virtual marketing of the firms will get the bottom of the market. Experienced virtual experts will assist the firms in the organizations such as focusing on demand, creating and making virtual trips together with the customer using the tactics of virtual story telling by videos. Firms will combine online marketing, social media and content. Thus, loyalty to the firm or brand will reawaken. It will significantly come together with marketing and sales. Marketing from one firm to many persons and personal sales from one firm to individual customers will begin to use the same techniques to create content and establish real-time connections focusing on the customers. Sales promotion activities and advertisements will be personal. The best firms will not see the marketing and sales as different departments. Firms that focus on creating customer value will combine both functions. Calls between the district sales managers working in the field and the head office will be made by online video calls. Number of workers in the general sales directorate in the head office will be reduced. Field sales organization will consist of the salespersons of other companies not subordinate to the firm's staff. All range of products and services will be sold through network marketing (Alter, 2013; Brouwer,2017; Galeon, Reed, 2017; Singh,2017).

Marketing will be obsessed with harmonization with its target audience. Information will be given to everyone from top management to junior officers to improve virtual marketing applications. Clicking data will give information about the social media and instant status of an individual. However, it will not be sufficient to understand the events between hearing the advertisement message and getting into the act of buying. Modern changes and the rising trend in marketing will be at the ultimate superiority of the data received from mobile devices. It will not overlook the factors such as clicking data, word of mouth marketing and the effect of traditional press advertisements on the buying process. Mobil devices will combine both offline and online marketing activities and move to take a decision based on customer behaviors (Kotler, Kartajaya, Setiawan, 2017). 
Analysis and effective use of complex numerical data will increase. It will create pressure for the firms to measure the complex efforts of the marketing department correctly, and on a real-time basis, in the presence of continuous expansion of the mobile devices and alternative distribution channels. The number of mediators and distributors in the marketing channel will increase. Advertising agencies, public relations firms, and the marketing departments of the firms will work more closely together. Data stored in the firms will be analyzed together, and more focus will be set on the distribution channels and creating customer experience. Marketing will continue to be the work of the whole firm. Marketing will become more integrated not only with customers, but also with society, allowing sustainable applications for future use (Diane, Schouten, 2014; Odden, 2017).

In the last fifty years, the world economy has created an unbelievable welfare distribution in some societies. Despite this welfare, millions of poor people have emerged, an economy with a recession trend has caused too much unemployment, environmental hazards, and scarcity have emerged. The gap between the rich and the poor has enlarged. Particularly in the last two centuries, this model has emerged with relatively limited resources. It shapes the companies of our age in obviously broken ways. Unnecessary support, reaching approximately one trillion dollars per year, has created market obstacles that have unsettled the current economic model used to find different solutions. Current companies have created undesired products such as social inequality, ecocide and political deception. For this reason, the directors will work for the benefit of humanity only if there is an overall point of view and new incentives and legal arrangements are made. Only then is social equality ensured. Environmental hazards and loss decrease in this new system. Thus, high profit is obtained at all times. While the firms sustain this productivity and diversity, they should perform the sustainable activities sensitive to the environment, nature, and society with higher sense of responsibility. The companies that do this should disclose the external benefits and costs to the public more openly. Firms should provide to investors and final consumers more information than shelf price or investment rate of return. Tax legislation should be based on the taxation of the bad actions instead of good actions. Advertisements should provide real information to the consumers beyond giving sales messages. Private sector, public bodies, and non-governmental organizations are required to perform different studies together (such as the Venus Project) for problems we encounter within today's complex economy, and no person or organization can easily solve them alone (in order to remedy the current status of the prominent firms) (Fresco, 2007; Stager, 2011; Sukhdev, 2012).

It is not easy to predict, forecast, and read the future. It is now clear thanks to available facilities and technology that the future is not a destination point or place. In fact, the future also has aspects which can be controlled, designed and changed as desired. Especially in firms, each director looking to the future is required to scientifically focus on future predictions which change according to different places, times, and customers (Friedman, 2016).

\section{Field Research and Measurement}

In the study, literature review and survey methods were applied as data collection methods. In this context, literature was reviewed, and the theoretical background of the study was prepared. Then, the target-specific survey was prepared, and the theoretical framework was tested with the field research. Measurement instrument is a research survey consisting of 17 questions, including the demographic information. The Five-level Likert scale was also used for the study. The main audience of the study are persons who work in the firms after graduating from Beykent University in the last twenty years. Sampling size is 26,959 graduates registered in the system. The convenience sampling method was used. The survey was made by sending a link to all sample associate, undergraduate, and master's degree holders whose communication data was recorded in the graduate's department. The link sent was left open for three months. It was reviewed by 234 persons and 104 graduates who participated in the field research. 


\begin{tabular}{|c|c|c|c|c|c|c|c|c|}
\hline & \multirow[b]{2}{*}{ Variables } & \multirow[b]{2}{*}{$\begin{array}{l}\text { Descriptive } \\
\text { Statistics }\end{array}$} & \multicolumn{5}{|c|}{ Level of Participation in the Judgments } & \multirow[t]{2}{*}{ Totals } \\
\hline & & & $\begin{array}{c}1 . \\
\text { I strongly } \\
\text { disagree }\end{array}$ & $\begin{array}{c}2 . \\
\text { I do not } \\
\text { agree }\end{array}$ & $\begin{array}{c}3 . \\
\text { Neutral }\end{array}$ & $\begin{array}{c}4 . \\
\text { I agree }\end{array}$ & $\begin{array}{c}5 . \\
\text { I strongly } \\
\text { agree }\end{array}$ & \\
\hline \multirow{2}{*}{1} & \multirow{2}{*}{$\begin{array}{l}\text { Smart Solution and Simple } \\
\text { Service Provision }\end{array}$} & $\mathrm{f}$ & 7 & 10 & 13 & 40 & 34 & 104 \\
\hline & & $\%$ & $6,73 \%$ & $9,62 \%$ & $12,50 \%$ & $38,46 \%$ & $32,69 \%$ & $100 \%$ \\
\hline \multirow{2}{*}{2} & \multirow{2}{*}{$\begin{array}{l}\text { Using New Technologies and } \\
\text { Applications }\end{array}$} & $\mathrm{f}$ & 12 & 8 & 19 & 37 & 28 & 104 \\
\hline & & $\%$ & $11,54 \%$ & $7,69 \%$ & $18,27 \%$ & $35,58 \%$ & $26,92 \%$ & $100 \%$ \\
\hline \multirow{2}{*}{3} & \multirow{2}{*}{$\begin{array}{l}\text { Recognition in Social Media } \\
\text { and Public Opinion }\end{array}$} & $\mathrm{f}$ & 8 & 5 & 12 & 37 & 42 & 104 \\
\hline & & $\%$ & $7,69 \%$ & $4,81 \%$ & $11,54 \%$ & $35,58 \%$ & $40,38 \%$ & $100 \%$ \\
\hline \multirow{2}{*}{4} & \multirow{2}{*}{$\begin{array}{lll}\text { Planning } & \text { the } & \text { Marketing } \\
\text { Activities } & & \end{array}$} & $\mathrm{f}$ & 6 & 12 & 14 & 52 & 20 & 104 \\
\hline & & $\%$ & $5,77 \%$ & $11,54 \%$ & $13,46 \%$ & $50,00 \%$ & $19,23 \%$ & $100 \%$ \\
\hline \multirow{2}{*}{5} & \multirow{2}{*}{ Realization of Future } & $\mathrm{f}$ & 9 & 15 & 16 & 44 & 20 & 104 \\
\hline & & $\%$ & $8,65 \%$ & $14,42 \%$ & $15,38 \%$ & $42,31 \%$ & $19,23 \%$ & $100 \%$ \\
\hline \multirow{2}{*}{6} & \multirow{2}{*}{$\begin{array}{l}\text { Creative Product and Service } \\
\text { Innovations }\end{array}$} & $\mathrm{f}$ & 5 & 7 & 10 & 39 & 43 & 104 \\
\hline & & $\%$ & $4,81 \%$ & $6,73 \%$ & $9,62 \%$ & $37,50 \%$ & $41,35 \%$ & $100 \%$ \\
\hline \multirow[t]{2}{*}{7} & \multirow{2}{*}{$\begin{array}{l}\text { Increase in the Number of } \\
\text { Suppliers }\end{array}$} & $\mathrm{f}$ & 6 & 16 & 21 & 46 & 15 & 104 \\
\hline & & $\%$ & $5,77 \%$ & $15,38 \%$ & $20,19 \%$ & $44,23 \%$ & $14,42 \%$ & $100 \%$ \\
\hline \multirow{2}{*}{8} & \multirow{2}{*}{$\begin{array}{l}\text { Increase in the Customer } \\
\text { Expenditures }\end{array}$} & $\mathrm{f}$ & 5 & 15 & 21 & 41 & 22 & 104 \\
\hline & & $\%$ & $4,81 \%$ & $14,42 \%$ & $20,19 \%$ & $39,42 \%$ & $21,15 \%$ & $100 \%$ \\
\hline \multirow{2}{*}{9} & \multirow{2}{*}{$\begin{array}{l}\text { Marketing Plan Application and } \\
\text { Control }\end{array}$} & $\mathrm{f}$ & 7 & 10 & 22 & 49 & 16 & 104 \\
\hline & & $\%$ & $6,73 \%$ & $9,62 \%$ & $21,15 \%$ & $47,12 \%$ & $15,38 \%$ & $100 \%$ \\
\hline \multirow{2}{*}{10} & \multirow{2}{*}{$\begin{array}{l}\text { Increase in the Number of } \\
\text { Intermediaries and Distributors }\end{array}$} & $\mathrm{f}$ & 4 & 11 & 17 & 47 & 25 & 104 \\
\hline & & $\%$ & $3,85 \%$ & $10,58 \%$ & $16,35 \%$ & $45,19 \%$ & $24,04 \%$ & $100 \%$ \\
\hline \multirow{2}{*}{11} & \multirow{2}{*}{$\begin{array}{l}\text { Increase in the Competitors and } \\
\text { Change of Quality }\end{array}$} & $\mathrm{f}$ & 8 & 4 & 9 & 42 & 41 & 104 \\
\hline & & $\%$ & $7,69 \%$ & $3,85 \%$ & $8,65 \%$ & $40,38 \%$ & $39,42 \%$ & $100 \%$ \\
\hline \multirow{2}{*}{12} & \multirow{2}{*}{$\begin{array}{l}\text { Analysis of Social Media } \\
\text { Channels }\end{array}$} & $\mathrm{f}$ & 6 & 8 & 11 & 28 & 51 & 104 \\
\hline & & $\%$ & $5,77 \%$ & $7,69 \%$ & $10,58 \%$ & $26,92 \%$ & $49,04 \%$ & $100 \%$ \\
\hline \multirow{2}{*}{13} & \multirow{2}{*}{$\begin{array}{l}\text { Product and Service Price } \\
\text { Increase }\end{array}$} & $\mathrm{f}$ & 5 & 15 & 20 & 33 & 31 & 104 \\
\hline & & $\%$ & $4,81 \%$ & $14,42 \%$ & $19,23 \%$ & $31,73 \%$ & $29,81 \%$ & $100 \%$ \\
\hline
\end{tabular}

Table 1. Level of Participation in the Judgments

The variables regarding the level of participation in the judgments in Table 1 were examined and the findings are as follows:

1. Total percentage of persons who agree and strongly agree with the opinion that firms will present smart solutions and more simplified services in the future according to customer needs is $71.15 \%$ - very high.

2. Total percentage of persons who agree and strongly agree that the judgment regarding the use of new technologies, artificial intelligence, internet of things, robots, and similar new computer applications more by firms in the future for their products and services is $62,50 \%$ - a little above the medium.

3. Total percentage of persons who agree and strongly agree that the judgment regarding the increasing recognition of firms in social media and public opinion is $75,96 \%$ - high.

4. Total percentage of persons who agree that the judgment regarding planning marketing activities of the firms according to the future predictions in the external environment is $50 \%$ - medium.

5. Total percentage of persons who agree that the judgment regarding the firms and marketing departments should work to realize the future instead of hopefully waiting for the future is $42,31 \%$ - near the medium.

6. It will be highly important for the firms to introduce creative products and regularly make service innovations in the future. Total percentage of persons who agree and strongly agree with this judgment is $78,85 \%$ - high.

7. Total percentage of persons who agree that the judgment regarding the number of suppliers of firms will continuously increase is $44,23 \%$ - near medium. Firms should increase the number and quality of suppliers.

8. Total percentage of the persons who agree that the judgment regarding diversification and the change of expenditures made by the customers in the firm is $39,42 \%$ - near medium. Firms should make cross selling a priority to increase this rate.

9. Total percentage of persons who agree that the judgment regarding the marketing department should regularly plan, apply, control and analyze future activities is $47,12 \%$ - near medium. This percentage should be increased. 
10. Total percentage of persons who agree that the judgment regarding the increase in the number of intermediaries and distributers in the marketing channel is $45,19 \%$ - near medium. This percentage should be increased.

11. Total percentage of persons who agree and strongly agree that the judgment regarding the increase in the number and quality of the competitors in future is $79,80 \%$ - high.

12. Total percentage of persons who strongly agree that the judgment regarding social media channels should be analyzed and interpreted more carefully is $49,04 \%$. This may indicate that future marketing will be in the field of new media.

13. Total percentage of persons who strongly agree that the judgment regarding products and services should be sold at higher prices in future is $29,81 \%$, and this indicates that firms are required to give importance to marketing activities which create customer value to justify this price increase.

\begin{tabular}{|c|c|c|c|c|}
\hline & Variables & Normality & & \\
\hline \multirow{2}{*}{1} & \multirow{2}{*}{ Smart Solution and Simple Service Provision } & Sk &,- 964 & 238 \\
\hline & & $\mathrm{Ku}$ & ,138 & 472 \\
\hline \multirow{2}{*}{2} & \multirow{2}{*}{ Using New Technologies and Applications } & Sk &,- 779 & 238 \\
\hline & & $\mathrm{Ku}$ &,- 331 & 472 \\
\hline \multirow{2}{*}{3} & \multirow{2}{*}{ Recognition in Social Media and Public Opinion } & Sk & $-1,253$ & 238 \\
\hline & & $\mathrm{Ku}$ & ,907 & 472 \\
\hline \multirow{2}{*}{4} & \multirow{2}{*}{ Planning the Marketing Activities } & Sk &,- 899 & 238 \\
\hline & & $\mathrm{Ku}$ & 243 & 472 \\
\hline \multirow{2}{*}{5} & \multirow{2}{*}{ Realization of Future } & Sk &,- 663 & 238 \\
\hline & & $\mathrm{Ku}$ &,- 473 & 472 \\
\hline \multirow{2}{*}{6} & \multirow{2}{*}{ Creative Product and Service Innovations } & Sk & $-1,267$ & 238 \\
\hline & & $\mathrm{Ku}$ & 1,115 & 472 \\
\hline \multirow{2}{*}{7} & \multirow{2}{*}{ Increase in the Number of Suppliers } & Sk &,- 590 & 238 \\
\hline & & $\mathrm{Ku}$ &,- 343 & 472 \\
\hline \multirow{2}{*}{8} & \multirow{2}{*}{ Increase in the Customer Expenditures } & Sk &,- 561 & 238 \\
\hline & & $\mathrm{Ku}$ &,- 431 & 472 \\
\hline \multirow{2}{*}{9} & \multirow{2}{*}{ Marketing Plan Application and Control } & Sk &,- 811 & 238 \\
\hline & & $\mathrm{Ku}$ & 240 & ,472 \\
\hline \multirow{2}{*}{10} & \multirow{2}{*}{ Increase in the Number of Intermediaries and Distributors } & Sk &,- 805 & 238 \\
\hline & & $\mathrm{Ku}$ &, 166 & 472 \\
\hline \multirow{2}{*}{11} & \multirow{2}{*}{ Increase in the Competitors and Change of Quality } & Sk & $-1,409$ & ,238 \\
\hline & & $\mathrm{Ku}$ & 1,490 & 472 \\
\hline \multirow{2}{*}{12} & \multirow{2}{*}{ Analysis of Social Media Channels } & Sk & $-1,238$ & ,238 \\
\hline & & $\mathrm{Ku}$ & ,630 & 472 \\
\hline \multirow{2}{*}{13} & \multirow{2}{*}{ Product and Service Price Increase } & Sk &,- 573 & ,238 \\
\hline & & $\mathrm{Ku}$ &,- 630 & 472 \\
\hline
\end{tabular}

Table 2. Distribution of Variables

In Table 2, normality tests are given and analyzed to determine whether the available data complies with the normal distribution range. As a result of the normality control, although the p values were mainly higher than 0,05 , Skewness and Kurtosis values were examined, and some conclusions were reached (whether the data is distributed normally or not). In the Table, Skewness is referred to as $S k$, and Kurtosis is referred as $K u$. Accordingly, as the Skewness and Kurtosis values for all variables are obtained in the desired range of $-2,-3$ and $+2,+3$, it indicates that the data collected in the study is distributed normally (Cooper and Schindler, 1998; Schwab, 1999).

\begin{tabular}{|l|l|l|l|l|}
\hline & f & \% & Valid \% & Cumulative \% \\
\hline $\mathbf{2 1}$ and below & 8 & $7,69 \%$ & $7,69 \%$ & $7,69 \%$ \\
\hline $\mathbf{2 2}-\mathbf{2 6}$ & 37 & $35,58 \%$ & $35,58 \%$ & $43,27 \%$ \\
\hline $\mathbf{2 7}-\mathbf{3 5}$ & 29 & $27,88 \%$ & $27,88 \%$ & $71,15 \%$ \\
\hline $\mathbf{3 6}-\mathbf{4 9}$ & 27 & $25,96 \%$ & $25,96 \%$ & $97,12 \%$ \\
\hline $\mathbf{5 0}-\mathbf{6 4}$ & 3 & $2,88 \%$ & $2,88 \%$ & $100,00 \%$ \\
\hline Total & 104 & $100,00 \%$ & $100,00 \%$ & \\
\hline
\end{tabular}

Table 3. Frequency and Percentage Values for the Age Variable

As it is understood from Table 3, 8 of the graduates in the sample group (7,69\%) are 21 and below. The group in the age range of 22-26 consists of 37 persons and it is the most crowded group with $35.58 \%$. The percentage of 
the group in the age range of $27-35$ and $36-49$ is $27.88 \%$ and $25.96 \%$, respectively (which is very close to each other).

\begin{tabular}{|l|l|l|l|l|}
\hline & f & \% & Valid \% & Cumulative \% \\
\hline Male & 46 & $44 \%$ & $44 \%$ & $44 \%$ \\
\hline Female & 58 & $56 \%$ & $56 \%$ & $100 \%$ \\
\hline Total & 104 & $100 \%$ & $100 \%$ & \\
\hline
\end{tabular}

Table 4. Frequency and Percentage Values for Sex Variable

As seen in Table 4, the sample group consists of 104 graduates, 58 (56,0\%) female; 46 (44,0\%) male.

\begin{tabular}{|l|l|l|l|l|}
\hline & f & \% & Valid \% & Cumulative \% \\
\hline Associate & 22 & $21 \%$ & $21 \%$ & $21 \%$ \\
\hline Undergraduate & 49 & $47 \%$ & $47 \%$ & $68 \%$ \\
\hline Master & 33 & $32 \%$ & $32 \%$ & $100 \%$ \\
\hline Total & 104 & $100 \%$ & $100 \%$ & \\
\hline
\end{tabular}

Table 5. Frequency and Percentage Values for Graduation Status Variable

According to Table 5, 22 of the graduates in the sample group (21\%) declared that they received College/associate level, $49(47 \%)$ at Faculty/undergraduate level, and 33 (32\%) at master level in Beykent University Institutes.

Predictions in this field research vary by the branch of industry of the firms, goods produced, and services offered by the firms. The firms will be affected more by events in their external environments and each firm will determine its destiny at the common point uniting these differences.

An important aspect of this will be to find which of the changes and trends summarized in the predicted tables will be most important for marketing activities in the future. Yet, the future of the firms will be determined by the complex, unforeseen, and random events. Furthermore, various unknown factors which cannot be predicted today will also play a part.

Prediction trends study that indicates the variables are distributed normally may help the firm directors and marketing managers to take new opportunities for mixed marketing, target markets, and product positioning.

TRENDS AND PREDICTIONS ARE ANALYZED

\author{
ए \\ FIRM MACRO EXTERNAL ENVIRONMENT FACTORS ARE EVALUATED \\ Demographic-Natural-Cultural-Economic-Political-Technological Environment \\ MARKETING MICRO EXTERNAL ENVIRONMENT FACTORS ARE EVALUATED \\ Public Opinion-Suppliers-Competitors-Distributors-Customers

\section{CUSTOMER VALUE IS CREATED}

Table 6. Summary of the Study

In Table 6, the factors analyzed in the study are summarized as a conceptual model. The trends and predictions are analyzed. The attainment of customer value creation (targeted by the marketing department) is studied (with the evaluation of future predictions by the firm management in the field). If the firm management takes decisions according to future macro external environment factors, it may succeed in creating customer value. If the marketing management can act according to future micro external environment factors, it may succeed in creating customer value. The firm must evaluate the macro external environmental factors. These factors are demographic, natural, cultural, economic, political, and technological environments. Marketing evaluation should also be based on micro external environmental factors. These are public opinion, suppliers, competitors, distributors, and customers.

\title{
Conclusion
}

The judgments on new trends analyzed in this study:

(1) Our firm will provide smart solutions and simple services for the customer's needs in the future.

(2) Our firm will use more new technologies, artificial intelligence, internet of things, robots, and similar new computer applications in its products and services.

(3) Our firm will be recognized more in social media instruments and public opinion.

(4) Marketing activities by our firm are planned according to future predictions in the external environment. 
(5) Our firm and the marketing department will work to realize the future instead of hopefully waiting.

(6) It will be highly important for our firm to introduce creative products and make service innovations regularly in the future.

(7) The number of suppliers of our firm will continuously increase.

(8) The expenses made by our customers in the firm will diversify and dramatically change.

(9) Our marketing department will regularly plan, implement, control and analyze future activities.

(10) The number of mediators and distributors in marketing will increase.

(11) The number and quality of our competitors will increase in the future.

(12) Social media channels will be analyzed and interpreted more carefully.

(13) Our products and services will be sold at higher prices in the future.

The rate of participation in the tables summarized in this study may remain constant, increase, or decrease in time. However, general situations may arise in different ways in the future. We can specify the general situation in each market as a trend. The firms which would like to mature without getting old are required to make innovations and perform scientific marketing activities continuously, under the harsh and wild global competition, in order to be long-lasting. Conversion and change for the individual person in successful firms will be made by directors working at medium and low level, not at the highest level. All directors assigned at medium and intermediary positions will examine and find problems with the support of top management, and immediately act after making a decision.

Today will be tomorrow soon. For all firms and their directors, today will become history. Firms and marketing directors will now work at a higher speed to realize the future instead of waiting for it. Marketing will consider different (and new) trends explained here to create customer value.

As a solution, every firm director will take concrete steps in the application and performance of total marketing activities to create customer value. Consequently, it will become difficult to predict the future. Thus, the future of the firms will be pictured and designed to some extent and changed.

\section{References}

- Alter, Shannon 2013. “Lean into The Curve: 3 Marketing Trends not to Ignore”, Journal of Property Management, May/Jun 78:3, 14.

- Brouwer, Bree 2017. “Three Significant Video Trends for Perfecting Your 2018 Content Marketing Strategy”, November/December, Content 37, http://web.a.ebscohost.com/08.01.2018.

- Cooper, Donald R. and Pamela S. Schindler, 1998. Business Research Methods, McGraw-Hill International Editions, Boston.

- Dixon, Patrick 2017. "10 Trends That Will Dominate Our Future - All Predictable, Changing Slowly with Huge Future Impact - Based on New Book the Future of Almost Everything”, www.globalchange.com/02.01.2018.

- Fresco, Jacque 2007. “Designing the Future”, www.thevenusproject.com/02.01.2018.

- Friedman, George 2012. the Next Decade-Empire and Republic in a Changing World, Anchor Books, New York.

- Friedman, Thomas L. 2016. Thank You for Being Late-An Optimist's Guide to Thriving in the Age of Accelerations, Allen Lane-Penguin Books, Great Britain.

- Gunn, Ronald A. 2013. Matrix Management Success-Method Not Magic, Infinity Publishing, USA.

- Galeon, Dom and Christiana Reed 2017. "Kurzweil Claims That the Singularity Will Happen by 2045”, https://futurism.com/30.01.2018.

- Jánszky, Sven Gábor 2017. “2020 - Our Life in the Future and Five Predictions for Business”, Insight 2011 International, http://xlgroup.com/13.02.2018.

- Kaku, Michio 2017. "The Future of the Mind: The Scientific Quest to Understand, Enhance, and Empower the Mind”, http://mkaku.org/02.01.2018.

- Kotler, Philip and Gary Armstrong 2018. Principles of Marketing, 17e Global Edition, Pearson, Boston.

- Kotler, Philip and Herwan Kartajaya, Iwan Setiawan 2017. Marketing 4.0-Moving from Traditional to Digital, John Wiley and Sons, New Jersey.

- Kurzweil, Ray 2001. "The Age of Intelligent Machines | Knowledge Processing-From File Servers to Knowledge Servers”, www.kurzweilai.net/02.01.2018.

- $\quad$ Leonhard, Gerd 2017. "How Will Humanity Prevail in the Face of Rapid and All-Encompassing Technological Change?” www.futuristgerd.com/02.01.2018. 
- Odden, Lee 2017. “Marketing Trends \& Predictions for 2017”, http://www.toprankblog.com/ 11.02.2018.

- Paul, Dan and Jeff Cox 2003. The Cure-Enterprise Medicine for Business, John Wiley and Sons, New Jersey.

- Peters, Brad 2017. “Data Science: Getting Real”,www.forbes.com/ 13.01.2018.

- Ranchhod, Ashok 2004. "The Changing Nature of Cyber-Marketing Strategies", Business Process Management Journal, 10: 3, 262 - 276/ www.emeraldinsight.com/ 15.02.2018.

- Roubini, Nouriel 2017. "Three Scenarios for the Global Economy ...", www.dunya.com/30.02.2018.

- Schouten, John and Diane Martin 2014. Sustainable Marketing, New International First Edition, Pearson, England.

- Schwab, Donald P. 1999. Research Methods for Organizational Studies, Lawrence Erlbaum Associates Publishers, London.

- Singh, Sunil 2017. “5 Digital Marketing Trends that will Remain in 2017”, Gulf Marketing Review, Dubai, https://search.proquest.com/15.02.2018.

- Stager, Curt 2011. Deep Future-The Next 100,000 Years of Life on Earth, Thomas Dunne Books, New York.

- Stone, Merlin David and Neil David Woodcock 2014 "Interactive, Direct and Digital Marketing a Future That Depends on Better Use of Business Intelligence”, Journal of Research in Interactive Marketing 8: 1, 4-17/ www.emeraldinsight.com/ 23.01.2018.

- Sukhdev, Pavan 2012. Corporation 2020-Transforming Business for Tomorrow's World, Island Press, Washington.

- “The 5 Most Prominent Management Trends of the 21st Century” 2017. International Business Times, http://www.ibtimes.com/01.02.2018.

- Walsh, Mike 2017. "Marketing Topics”, www.mike-walsh.com/01.02.2018.

- Watson, Richard 2012. Future Files-A Brief History of the Next 50 Years, Nicholas Bradley Publishing, London.

- Wheelwright, Verne 2011. The Personal Futures Workbook, Fourth Edition, www.personalfutures.net/30.01.2018. 